\title{
Use of salmeterol/fluticasone combination (Seretide) in an asthma clinic: a pragmatic open study from primary care
}

\author{
Christopher E Clark
}

\begin{abstract}
Aims: The salmeterol/fluticasone combination inhaler (Seretide) has been shown to be effective in the management of asthma by randomised controlled trials. This study examined whether it was also effective in clinical use in primary care.

Methods: Patients attending the surgery asthma clinic with persistent symptoms despite regular inhaled corticosteroid therapy were offered Seretide. Outcome measures were symptom scores, peak flow measurements, prescriptions for relief bronchodilators, mean daily inhaled steroid dosage, and asthma treatment costs. Patients were assessed at baseline, 9 and 19 months, comparing Seretide users with other asthma clinic attenders.

Results: Fifty patients were studied, 20 started Seretide. Symptom scores at entry were higher for Seretide patients than the comparison group (total score 4.2 vs $1.5 ; \mathrm{p}<0.001$ ), and reduced with Seretide, to levels below those seen in the comparison group.
\end{abstract}

Study patients use of relief devices was similar at outset but significantly lower at 9 month follow up (mean 0.7 vs 2.1; 95\%CI difference 0.4 to $2.4 ; \mathrm{p}<0.01$ ). Daily dosages of inhaled steroid were significantly higher at entry for the Seretide group (mean 908mcgs vs $648 ; \mathrm{p}=0.041$ ) and were reduced with Seretide to $476 \mathrm{mcgs}$ at 9 months $(p=0.002)$ and 467 mcgs $(p=0.008)$ at 19 months. Mean 6 month treatment costs for study patients were higher at entry ( $£ 146.85$ vs $£ 82.74 ; p=0.12$ ), rose with the addition of Seretide at 9 months ( $£ 165.27$ vs $£ 80.92 ; p=0.001$ ) but were significantly reduced at 19 months( $£ 97.35$ vs $£ 72.96$; $p=0.35$, Seretide patients' mean cost reduction $£ 67.92 ; 95 \% \mathrm{CI} £ 21.24$ to $£ 114.60 ; \mathrm{p}<0.01$ ).

Conclusions: Seretide is effective in treating symptomatic asthma in primary care, reducing symptom scores, reliever use, and mean daily steroid requirements. When symptoms are taken into account, it also appears to be cost-effective, and treatment costs are reduced after extended follow up without loss of benefit.

\section{Introduction}

In the treatment of asthmatics with persistent symptoms at step two of the British Thoracic Society (BTS) asthma guidelines ${ }^{1}$ there is evidence that the addition of a long acting ß2-agonist produces better improvement in symptom control and spirometry, and reduces the use of reliever medication when compared with an increased dose of inhaled corticosteroid. ${ }^{2}$ The introduction of the salmeterol/fluticasone combination inhaler (Seretide, ${ }^{\circledR}$ GlaxoSmithKline), offers a single delivery device for patients requiring this combination. This device has also been shown to be more effective than increasing doses of inhaled corticosteroids ${ }^{3,4}$ and is as effective as the two compounds inhaled separately. ${ }^{5-7}$ Evidence to date has been exclusively derived from double blind randomised controlled trials, mostly in secondary care settings, and similar results cannot always be assumed, for reasons such as compliance, or inclusion criteria, when treating individual patients in primary care. ${ }^{8}$ Pragmatic trials of a new product in the primary care setting can provide confirmation that the treatment effects demonstrated by randomised controlled trials can be realised in everyday clinical practice. ${ }^{9}$ Use of this new product is also likely to add to a practice's drug costs for asthma treatment. This study was planned therefore, as a pragmatic examination of the effects of Seretide on symptoms, and objective measures of asthma control, in patients attending a nurse-run asthma clinic in one rural dispensing general practice, and to measure the cost implications.

\section{Methods}

The practice covers a rural population of 4,500 from three surgeries. There are 1,850 registered at the author's surgery where this study was undertaken. In the disease register 204 (11\%) have a recorded diagnosis of asthma and during the study period 70 patients (34\% of registered asthmatics) attended the nurse-run asthma clinic.

In the clinic day, night and activity symptom scores ranging from 0 (never) to 3 (daily) over the previous four weeks are recorded according to the Tayside scoring system, ${ }^{10}$ thus symptom scores ranged from a possible zero (no symptoms) to nine. Potential subjects were identified in the clinic if they were taking regular inhaled corticosteroid treatment (i.e. on step 2 to 3 of the BTS asthma guidelines). They were offered treatment with Seretide in an Accuhaler ${ }^{\circledR}$ device if they had stable but symptomatic asthma (symptom scores $\geq 2$ ). Patients with controlled asthma (symptom scores $<2$ ) at step 2 were designated as the comparison group.

Prescriptions of all inhaled therapy and oral steroid courses in the previous six months were recorded. Follow up data on patients were extracted from further clinic attendances after six and 12 months. At these reviews steroid doses were stepped down if symptom scores were less than 2. Data were analysed to compare symptom scores, PEF measurements, and use of relief bronchodilators and oral steroids. Mean daily-inhaled steroid dosages over the six months prior to each review were calculated from dispensing records (according to the formula: no of units prescribed X no of doses per unit X dose strength / 182.5 days). If fluticasone was prescribed the dosage was doubled to calculate an equivalent daily dosage of beclomethasone. Total drug costs were calculated using current approved NHS prices.

Results were analysed on an intention-to-treat basis using SPPSS for Windows v9.0 and compared using independent or paired samples t-tests, where normally distributed, or appropriate non parametric tests as indicated in the results. Normal distributions were tested using the Kolmogorov-Smirnov test. Patient

\section{Dr Christopher Clark}

General Practitioner

Correspondence to:

Dr Chris Clark

The Mid Devon Medical Practice, School Surgery, Fore Street, Witheridge, Devon, EX16 8AH

Tel: +44 (0)1884 860205 Fax: +44 (0)1884 860887 Email:

Chris.Clark@gp-L83023.nhs.uk

Date submitted: 08/04/03

Date Accepted: 10/08/03

Prim Care Resp J 2003; 12(3):86-89 
Original research

For personal use only,

Not to be reproduced without the permission of the Primary Care Respiratory Journal

\begin{tabular}{|c|c|c|c|}
\hline Table 1. Patient details & Seretide Group & Comparison Group & Significance \\
\hline $\mathrm{N}$ & 20 & 30 & \\
\hline Mean Age (95\%CI) & 46 (36 to 55$)$ & 46 (37 to 56$)$ & $\mathrm{p}=0.96 *$ \\
\hline Male/Female & $26 \% / 74 \%$ & $33 \% / 67 \%$ & $\mathrm{p}=0.53^{\#}$ \\
\hline No of smokers & 0 & 5 & $\mathrm{p}=0.075 \dagger$ \\
\hline Existing salmeterol users & 5 & 10 & $\mathrm{P}=0.53^{\#}$ \\
\hline $\begin{array}{l}\text { Mean predicted } \\
\text { PEFR }(95 \% \mathrm{CI})\end{array}$ & $461(422$ to 500$)$ & $444(399$ to 488$)$ & $\mathrm{p}=0.23^{*}$ \\
\hline
\end{tabular}

Table 2. Mean symptom scores and PEFR measurements

Entry

Seretide Group Comparison Group Significance

Day

Night

Activity

Total

PEF

\%predicted PEF

Courses of oral steroids

Mean daily inhaled

steroid dosage

Mean no of bronchodilators

in previous 6 months $(95 \% \mathrm{CI})$

Mean cost of 6 months prior

treatment $(95 \% \mathrm{CI})$

\section{First follow up}

Day

Night

Activity

Total

PEF

\%predicted PEF

Courses of oral steroids

Mean daily inhaled steroid dosage

Mean no of bronchodilators

in prior 6 months $(95 \% \mathrm{CI})$

Mean cost of prior 6 months

treatment $(95 \% \mathrm{CI})$

\section{Second follow up}

Day

Night

Activity

Total

PEF

\%predicted PEF

Courses of oral steroids

Mean daily inhaled

steroid dosage

Mean no of bronchodilators

in prior 6 months $(95 \% \mathrm{CI})$

Mean cost of prior 6 months

treatment $(95 \% \mathrm{CI})$

*Mann Whitney U test

$\propto$ Pearson's chi square test

$\ddagger \mathrm{p}=0.015$; Wilcoxon Signed Ranks Test

$\mu \mathrm{p}=0.008$; Wilcoxon Signed Ranks Test

\section{4}

1.2

1.7

$4.2^{\int}+$

441

95

2

$908 \alpha \mu$

2.7 (1.7 to 3.6)

$£ 146.85$

(£69.90 - £223.80)

0.3

0.4

0.5

$1.2^{\jmath}$

414

93

1
$476 \alpha$

0.7 (0.2 to 1.1$)$

2.1 (1.2 to 3.0$)$

$£ 80.92$

0.7

0.2

0.7

1.5

388

88

4

648

2.3 (1.5 to 3.1 )

$£ 82.74$

(£48.80 - £116.60)

$\mathrm{p}=0.043^{*}$

$\mathbf{p}<0.001 *$

$\mathrm{p}=0.002 *$

$\mathbf{p}<0.001$ *

$\mathrm{p}=0.22 \dagger$

$\mathrm{p}=0.30 \dagger$

$\mathrm{p}=0.31 \propto$

$\mathrm{p}=0.041$ *

$\mathrm{p}=0.56 \dagger$

$\mathrm{p}=0.12 \dagger$

0.6

0.5

0.7

1.8

426

99

1

536

$\mathrm{p}=0.66^{*}$

$\mathrm{p}=0.99 *$

$\mathrm{p}=0.54 *$

$\mathrm{p}=0.58^{*}$

$\mathrm{p}=0.75 \dagger$

$\mathrm{p}=0.61 \dagger$

$\mathrm{p}=0.778$

$\mathrm{p}=0.010$ *

$\mathbf{p}=\mathbf{0 . 0 0 7} \dagger$

$\mathrm{p}=0.001 \dagger$

( $£ 47.73$ to $£ 114.11$ )

0.7

0.2

0.7

$1.4 \ddagger$

412

96

2

$467 \mu$

0.8

0.7

0.9

2.1

408

96

2

512

$\mathrm{p}=0.95^{*}$

$\mathrm{p}=0.19$ *

$\mathrm{p}=0.94 *$

$\mathrm{p}=0.98 *$

$\mathrm{p}=0.93 \dagger$

$\mathrm{p}=0.98 \dagger$

$\mathrm{p}=0.51 \propto$

$\mathrm{p}=0.56^{*}$

$$
\begin{array}{rr}
1.2(0.6 \text { to } 1.8) & 2.1(1.3 \text { to } 3.0) \\
£ 97.35 \pm & £ 72.96
\end{array}
$$

(£62.12 to $£ 132.58$ )

(£37.33 to £108.59)

$\mathrm{p}=0.10 \dagger$

$\mathrm{p}=0.35 \dagger$

$\dagger$ independent samples t-test ${ }_{\mathrm{p}}^{\mathrm{p}=0.016 \text {; Wilcoxon Signed Ranks Test }}$ $\alpha p=0.002$; Wilcoxon Signed Ranks Test $\pm \mathrm{p}<0.01$; paired samples t-test
Figure 1. Flow diagram of study

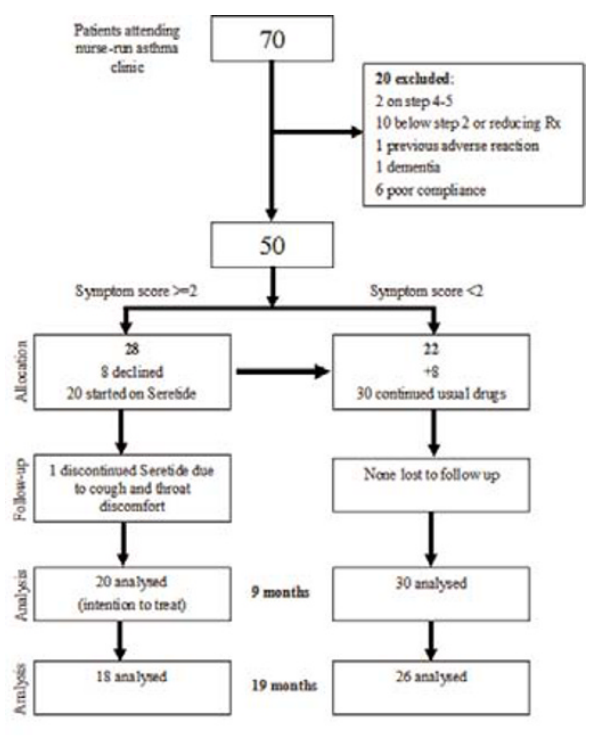

consent and ethical approval were not sought since this study was an observational study using routine asthma clinic and dispensing data, no additional patient contacts or information were sought, and the data were anonymised. The Seretide Evohaler was introduced in Jan 2001 and costs less than the Accuhaler. At this stage some first follow up appointments had been completed. Patients subsequently attending for follow up were offered the choice of changing to the Evohaler if they wished. The implications of this for the cost calculations are discussed below

\section{Results}

Fifty patients ( $71 \%$ of clinic attendees) were followed through the clinic (fig 1), of whom 20 were started on Seretide during the study period, and 30 acted as the comparison group. Patients did not differ significantly in age or sex distribution, PEF, salmeterol use or smoking status (table 1). All patients were reviewed at first follow up (mean 9 months). Eighteen study patients (90\%) and 26 (87\%) of the comparison group were reviewed at second follow up (mean 19 months).

The results are summarised in table 2. Those started on Seretide had significantly higher symptom scores at entry than the others. At follow up the symptom scores were unchanged in the comparison group, but were significantly reduced at 9 months in patients on Seretide to a level below that seen in the comparison group. The symptom scores for the Seretide group were significantly reduced at both 9 and 19 months compared with entry, but at 19 months the difference with the comparison group was no longer significant. No significant changes were observed in PEF or in prescriptions of oral steroids courses in the previous six months during the study.

The number of relief devices used in the previous 
Original research

For personal use only.

\section{Not to be reproduced without the permission of the Primary Care Respiratory Journal}

six months was significantly reduced after 9 months for the Seretide group compared to the others but the difference was no longer significant at 19 months. Mean equivalent daily dosages of beclomethasone at entry were significantly higher in the Seretide group compared to the others, and significantly reduced at both 9 and 19 months compared to baseline for the Seretide patients but not the comparison group (fig 2).

The mean cost of the previous six months' treatment was non significantly higher at entry for patients started on Seretide and rose to be significantly higher than the comparison group at 9 months. At 19 months the mean six month treatment costs for Seretide were $£ 67.92$ less (95\%CI £21.24 to £114.60; $\mathrm{p}<0.01)$ and significantly lower than at 9 months (fig 3 ).

\section{Discussion}

This study has demonstrated that asthmatics attending a primary care nurse run asthma clinic, who have persistent symptoms despite inhaled corticosteroids, can benefit from changing to Seretide. The adoption of a pragmatic open study design means that the results are more likely to be applicable to other primary care settings than previously published randomised placebo controlled trials.

The study patients' symptom scores were reduced to levels below those of control patients. Previous quality of life studies have also demonstrated greater improvements in symptom scores for Seretide than for salmeterol or increased inhaled steroids alone. ${ }^{11,12}$ These improvements were achieved with almost a $50 \%$ reduction of the mean equivalent daily dosage of inhaled steroid, and there was a significant fall in the use of relief medication. These benefits were sustained over the extended follow-up period.

Previous Swedish ${ }^{13}$ and British ${ }^{14}$ cost evaluations of double blind studies have shown that the absolute costs of treatment per patient rise when Seretide is introduced. If these costs are viewed in comparison to the increased number of symptom free days or "successfully treated" weeks then the use of Seretide in these settings appears to be more cost-effective than increasing doses of inhaled corticosteroids. The results of this study showed an increase of around $£ 20$ or $13 \%$ in the mean cost of six months treatment per patient given Seretide. However, as table 2 demonstrates, these patients were already costing approximately £10 per month more than well controlled patients at entry. If the improvements seen in symptom scores, inhaled steroid dosages, and use of relief inhalers is taken into account then use of Seretide appears to be justified for these patients in the primary care setting. The Seretide metered dose inhaler (MDI) was introduced after this study commenced and is cheaper than the Accuhaler device, thus it might be expected that the actual costs of introducing Seretide in practice would rise by less than this study suggests. The significant fall in Seretide treatment costs over the extended follow up period reflects transition to the MDI as it became available. Consequently, the costs of treatment at the 19 month follow up, which are lower than at entry, arguably provide a truer estimate of the impact of Seretide on a

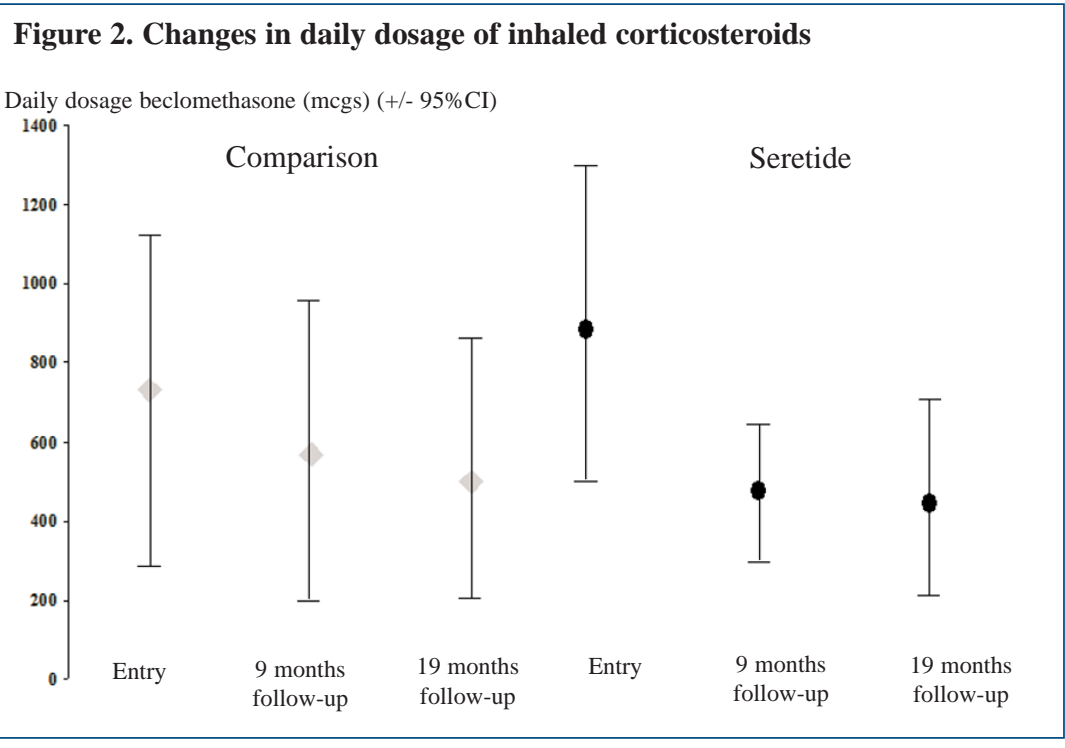

Figure 3. Mean costs of previous 6 months treatment

Mean cost for previous 6 months treatment (+/- 95\%CI)

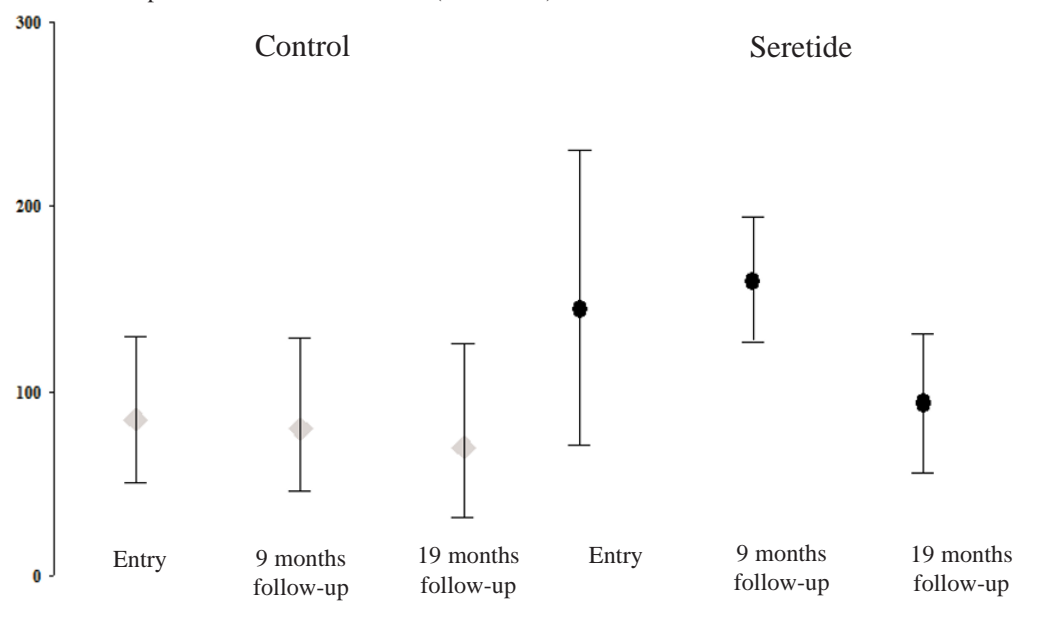

prescribing budget. The cost estimates presented are based on prescribing costs only. No allowance was made for the cost of appointments, but asthma clinics have been shown to reduce patient contacts by improving control and education, ${ }^{15}$ so no additional hidden costs were expected during the study.

This study was carried out in one rural dispensing surgery with an active nurse run asthma clinic. The numbers enrolled were small, thus it may not compare to larger primary care settings, although the management of asthma according to national guidelines should permit comparison. This study was not able to distinguish the benefits of adding salmeterol to patients already treated with inhaled corticosteroids from any specific benefits of Seretide. The latter is likely to offer the chance of increased compliance with therapy, is cheaper than using salmeterol and fluticasone separately, and costs the patient only one prescription charge. For these reasons it seems the more appropriate choice for patients requiring this combination of drugs.

In conclusion, this study provides evidence from primary care that the use of Seretide in patients with 
symptomatic asthma already on medium dose inhaled corticosteroids can produce significant reductions in symptom scores; use of relief medication; and mean daily inhaled steroid dosages. The additional initial costs and longer term changes in prescribing costs are demonstrated. In the light of this and other studies the addition of a long acting bronchodilator followed by conversion to a combination device in those who demonstrate benefit appears the most logical and cost effective approach to management. Careful and regular follow up is necessary to achieve the minimum maintenance dosage of inhaled steroid.

\section{Acknowledgements}

I wish to thank Mrs Brenda Jones who ran my asthma clinic for the last 9 years, before retiring, and the staff of School Surgery for their support. Also I thank Mrs Wenda Hobbs, Respiratory Nurse Advisor, who helped to collate the results, and Dr Colin Greaves who reviewed the manuscript.

\section{Conflict of Interests}

Brenda Jones was supported by an educational grant from GlaxoSmithKline. School Surgery has received patient education materials and record cards for asthma from GlaxoSmithKline.

\section{References}

1. The British Guidelines on Asthma Management. 1995 Review and Position Statement. Thorax 1995; 52: S1-S20.

2. Shrewsbury S, Britton M, Pyke S. Meta-analysis of increased dose of inhaled steroid or addition of salmeterol in symptomatic asthma (MIASMA) $B M J$ 2000;320:1368-73

3. Johansson G, McIvor RA, Purello D'Ambrosio F et al. Seretide (salmeterol $50 \mathrm{mcg} /$ fluticason propionate $100 \mathrm{mcg}$ bid) compared with budesonide (400mcg bid) in mild to moderate asthma. Am J Crit Care Med 1999; 159(3 part 2):A637 and poster presented at ATS meeting, San Diego, April 1999

4. Jenkins C, Woolcock AJ, Saarelainen P et al. Salmeterol/fluticasone propionate combination therapy $50 / 250$ mcg twice daily is more effective than budesonide $800 \mathrm{mcg}$ twice daily in treating moderate to severe asthma. Respir Med 2000; 94: 715-23.
5. Chapman KR, Ringdal N, Backer V et al. Salmeterol and fluticasone propionate (50/250mcg) administered via combination Diskus inhaler: As effective as when given via separate Diskus inhalers. Can Respir J 1999; 6(1): 45-51.

6. Aubier M, Pieters WR, Schlosser NJJ, Steinmetz KO. Salmeterol/fluticasone propionate $(50 / 500 \mathrm{mcg})$ in combination in a Diskus inhaler (Seretide) is effective and safe in the treatment of steroid-dependant asthma. Respir Med 1999; 93: 876-84.

7. Van den Berg NJ, Ossip M, Hederos CA et al. Salmeterol/fluticasone propionate $(50 / 100 \mathrm{mcg})$ in combination in a Diskus Inhaler (Seretide) is effective and safe in children with asthma. Pediatr Pulmonol 2000; 30: 97-105.

8. Sackett DL, Straus SE, Scott Richardson W et al. Evidence-based medicine: How to practice and teach EBM. 2nd ed. London: Churchill Livingstone, 2000:105-154.

9. Roland M,.Torgerson DJ. Understanding controlled trials: What are pragmatic trials? BMJ 1998;316:285. 10. Neville RG, Hoskins G, Clark R, McCowan C, Smith B. A standardized recording system to monitor asthma outcomes. Asthma Journal 2001;6.(4):193-96 11. Reese PR, Mather DB, Mahajan P, Woodring A Combination of salmeterol/fluticasone propionate via the Diskus improves quality of like in asthma patients. $J$ allergy Clin immunol 1999; 103 (1pt 2): S69, 265 12. Juniper EF, Jenkins C, Price MJ, et al. Quality of life of asthma patients treated with salmeterol/fluticasone propionate combination product and budesonide. Eur Respir J 1999; 14(Suppl 30): 370S, 2640.

13. Pieters WR. Lundback B. Sondhi S. et al. Costeffectiveness analysis of salmeterol/fluticasone propionate 50/500mcg vs fluticasone propionate $500 \mathrm{mcg}$ in patients with corticosteroid-dependent asthma V: Results. Pharmacoeconomics 1999; 16 (Suppl 2):29-34

14. Lloyd A, Browning D, Shrewsbury S. Costeffectiveness of salmeterol/fluticasone combination product and budesonide in the United Kingdom. Am J Respir Crit Care Med 2000; 161(3 pt 2): A197. 15. Charlton I. Asthma clinics: audit. The Practitioner 1989; 233: 1522-3. 